\title{
Pattern of Workplace Violence and Perceived Effects on Nurses' Work Productivity in Selected Hospitals in Ibadan, Oyo State
}

\author{
Oluwatosin O. Ope-babadele ${ }^{1} \&$ Rose E. Ilesanmi ${ }^{2}$ \\ ${ }^{1}$ School of Nursing Science, Babcock University, Ilisan Remo, Ogun State, Nigeria \\ ${ }^{2}$ Department of Nursing, University of Ibadan, Ibadan, Oyo State, Nigeria \\ Correspondence: Oluwatosin O. Ope-babadele, School of Nursing Science, Babcock University, Ogun State, \\ Nigeria. Tel: 234-703-080-0247.
}

Received: May 30, 2019

doi:10.20849/ijsn.v4i3.626
Accepted: August 29, 2019

Online Published: September 6, 2019

URL: https://doi.org/10.20849/ijsn.v4i3.626

\begin{abstract}
Background: Workplace violence (WPV) is a widespread occupational hazard affecting the health, safety, job attitude and productivity of the nursing workforce. This study was designed to investigate the pattern and perceived effects of WPV on nurses' work productivity in two selected hospitals in Ibadan.

Methods: This descriptive study was conducted in two purposively selected hospitals. Out of 1,418 nurses, 349 proportional sample was taken and respondents were selected using convenience sampling technique. Two validated questionnaires was used. Data were analysed using frequencies and percentages. Hypotheses were tested using chi-square at $\alpha=0.05$.

Results: Respondents' age was $39 \pm 6.5$ years; $46.8 \%$ were registered nurses, of which $48.1 \%$ had worked for 11-20 years. On pattern of violence, $49(15.6 \%)$ experienced physical violence without a weapon, 39(12.4\%) experienced verbal harassment and bullying. Attackers of 33(10.5\%) were patient relatives. Decreased work productivity due to WPV was reported $(60,19.1 \%)$ while no change in work productivity was reported(170, $54.1 \%$ ). Type of WPV was significantly associated with nurses productivity $\mathrm{x}^{2}=39.7 ; \mathrm{p}=0.001$.

Conclusion: Nurses experience violence in workplace commonly instigated by patient relatives. This affects job productivity. Strict implementation of policies on violence is required to enhance workplace safety and productivity.
\end{abstract}

Keywords: workplace violence, physical violence, nurses' work productivity, pattern, perceived effects

\section{Introduction}

\subsection{Introduction of Problem}

Violence at workplace has been a major subject of debate globally as it poses threat to all parties involved with far-reaching consequences. It is not limited by the type of occupation nor region, but cuts across all work settings (Khoshknab, Tamizi, Ghazanfari, and Mehrabani, 2012) and countries alike (Mohamad and Motasem, 2012). Violence at work refers to a broad spectrum of behaviours such as violent acts by patients, visitors, and/or co-workers which results in a concern for personal safety (Papa and Venella, 2013).

Globally, over a million people lose their lives as a result of violence at work (WHO, 2002 in Occupational Safety and Health Administration (OSHA), 2015). While about a million Britons experienced physical aggression in the workplace between 2009 and 2011, nearly 2 million American workers are victims of workplace violence each year (OSHA, 2015; Wurim, 2013) and unfortunately, many more cases go unreported (United States Department of Labour, 2011; Findorff, McGovern, Wall \& Gerberich, 2005 in OSHA, 2015). The situation is not any different in developing countries of Africa, Asia and Latin America ( Wurim, 2013).

According to Occupational Safety and Health Administration (OSHA, 2015), workers who provide services, work in remote or high crime areas, and those who work shift hours and/or have a great deal of contact with the public are the employees with the highest risk of encountering violence in the workplace. Shockingly, about $25 \%$ of violent accidents at work occur in the health sector, and over $50 \%$ of health workers have already experienced violence (Hahn, Hantikainen, Needham, Kok, Dassen, and Halfens, 2012). Clark (2016), submits that nurses are 
the most victimized group in the health care setting accounting for approximately $80 \%$ of all assaults with this number being under estimated.

Prevalence of WPV among nurses vary in different countries and settings, with rates reaching $29.9 \%$ in a public health facility in Ethiopia (Fute, Mengesha, Wakgari and Tessema, 2015) and 86.1\% ( $\mathrm{N}=416)$ in obstetrics and gynaecology departments in Egypt (Samir, Mohamed, Moustafa and Abou Saif, 2012). Workplace violence against nurses in Nigeria is no exception. Disturbing rates as high as $88.1 \%(\mathrm{~N}=303)$ was reported in a tertiary hospital in Abia state (Ogbonnaya, Ukegbu, Aguwa and Emma-Ukaegbu, 2012) and 53.5\% in a south-western city (Abodunrin, Adeoye, Adeomi and Akande, 2014).

Safety at workplace is a vital requirement in ensuring quality service delivery and optimal performance of the workforce. Available data shows that violence against workers can impact on the individual's health and morale, thus, negatively influencing productivity due to reduced morale and motivation (Azodo, Ezeja and Ehikhamenor, 2011).

Although violence at the workplace, specifically against nurses has been identified as a major occupational problem, the perceived effects of the violence on nurses' work productivity has been unknown. Hence, this study seeks to examine the pattern of nurses' exposure to workplace violence and its perceived effects on work productivity in selected health care settings in Ibadan, South-West Nigeria.

Specifically, the objectives of this study is to evaluate the proportion of nurses who had experienced workplace violence and determine the perceived effects of workplace violence on nurses' work productivity.

\subsection{Statement of Problem}

Workplace violence (WPV) is a serious global health problem. It has been reported as a significant issue for healthcare providers, including nurses and other staff directly involved in patient care (WHO, 2012). A position paper released by the Emergency Nurses Association (ENA) in 2010 recognized workplace violence as a serious occupational risk requiring targeted responses from employers, law enforcement agencies and the community, with the assertion that the health care industry leads all other sectors in the incidence of nonfatal workplace assaults.

Violence against nurses at the workplace is an alarming problem in both developed and developing countries (Al-Omari, 2015). It is prevalent and consequential, contributing to nurses' reduced health and safety, worsened job attitudes, and compromised productivity (Liu-Qin, Paul, Chu-Hsiang, Mary and Julie, 2012). This recognition of violence in health care has been demonstrated throughout the literature. The National Occupational Safety and Health (NIOSH, 2015) has gone a long way to establish guidelines to address workplace violence in health care. There is also a plethora of research on workplace violence and nursing. Spector, Zhou and Che (2014) completed a systemic review of nurses' exposure to violence, where it was stated that there have been 100 and more published articles on the incidence of workplace violence. It was also established that the highest incidence of workplace violence in nursing is in the areas of psychiatry, emergency medicine, and geriatrics (Spector, Zhou, and Che, 2013; Kowalenko, Gates, Gillespie, Succop and Mentzel, 2013; Nakaishi, Moss, Weinstein, Perrin, Rose, Anger et. al, 2013).

Despite the laudable achievements in the development of guidelines to prevent workplace violence in the health sector, recent events in the country (Nigeria) reveal an alarming incidence of violence against nurses. Sometime in May, 2004 at the male ward of the Neuropsychiatric Hospital, Aro, Abeokuta, as witnessed by the researcher, a patient slapped a female nurse while on duty. She was consequently referred to the University College Hospital, Ibadan where she was admitted for a substantive period of time as a result of hearing loss. This incidence consequently had an effect on the existing relationship between the nurses and all the patients on the ward. The nurses were angry and withdrawn, after which they refused to render their services to the patients. More recently, on February 11, 2016, at the University College Hospital, a patient relative slapped a nurse. This incidence also resulted in a 48 hour industrial action by the entire nursing workforce of the hospital (Guardian newspaper, 2016).

Based on these scenarios, the researcher can logically conclude that workplace violence is a frustrating problem of our time. While more and more information on the frequency of violence and how to handle it is becoming known, there is often no reasonable rationale for this type of conduct and, despite everything we know or do, violent situations happen. Research is needed to uncover the main determinants of workplace violence against nurses here in Nigeria, the experiences of nurses on violence and how it has affected nurses' work productivity. 


\subsection{Review of Literature}

\subsubsection{Workplace Violence}

The National Institute for Occupational Safety and Health (NIOSH) defines workplace violence as "violent acts (including physical assaults) directed toward persons at work or on duty" (Department of Health and Human Services [DHHS] 2012, in Papa and Venella, 2013).

Workplace violence is any act or threat of physical violence, harassment, intimidation, or other threatening disruptive behaviour that occur at the work site, ranging from threats and verbal abuse to physical assaults and even homicide. Others include violence or the threat of violence against workers; acts of aggression or physical assault; threatening behaviours; or behaviour that causes emotional or physical harm to customers, co-workers, or managers in a work setting (McPhaul, Lipscomb and Johnson, 2010).

There are common themes that have remained constant over the years, essentially suggesting that the violence occurs at work and refers to a broad spectrum of behaviours (e.g., violent acts by patients, visitors, and/or co-workers) which consequently results in a concern for personal safety (Papa and Venella, 2013).

Workplace violence is a far more common feature in organizations than previously thought. While there is a record of about a million Britons who have experienced physical aggression in the workplace between 2009 and 2011, approximately 2 million American workers are victims of workplace violence each year and many more go unreported (USDA, 2011). This situation is similar in the developing countries of Africa, Asia and Latin America (Clark, 2016; Wurim, 2013).

\subsubsection{Proportion and Frequency of Workplace Violence}

The Bureau of Labour and Statistics (BLS) reported that health care workers were victims of approximately 11,370 assaults in 2010 which was a $13 \%$ increase over the number reported in 2009 and $19 \%$ of which occurred in nursing (NIOSH, 2015). Among all health care workers, nurses have the highest risk for violence in the workplace with over 30,000 reported incidents of violence in the United States (Harrell, 2011). These numbers account for reported workplace violence and the actual number of violence in nursing may be considerably higher, as supported by Ogbonnaya, Ukegbu, Aguwa and Emma-Ukaegbu, (2012), that there is limited data on the magnitude of workplace violence. The number of incidence of assault may be $80 \%$ higher because research suggests that individuals in the health care underestimate the incidence of violence they experience while on duty.

The prevalence of WPV has always presented a picture of concern. From 2002 to 2013, incidents of serious workplace violence (those requiring days off for the injured worker to recuperate) were four times more common in healthcare than in private industry (OSHA, 2015). In 2013, it was recorded that the broad "healthcare and social assistance" sector had 7.8 cases of serious workplace violence per 10,000 full-time employees, while other large sectors such as construction, manufacturing, and retail all had fewer than two cases per 10,000 full-time employees (OSHA, 2015).

Clark's conclusion on Hader's study in the United States, Afghanistan, Taiwan, and Saudi Arabia, reported an $80 \%$ exposure of the respondents to violence within the work setting (Clark, 2016). In a study conducted by Nakaishi, et al (2013) in Oregon, it was concluded that $49.6 \%$ of nurses $(N=29,979)$ surveyed experienced violence within the work setting, of which $19.1 \%$ experienced physical violence and $46.3 \%$ experienced non-physical violence. In Slovenia, Kvas and Selijak (2014) reported that $61.6 \%$ of the nurses had experienced violence between 2013 and 2014. In another study conducted in Ladoke Akintola University Teaching Hospital, $53.2 \%$ of the nurses experienced violence in the past one year (Abodunrin, Adeoye, Adeomi and Akande, 2014). Hader's study noted a physical violence prevalence of $25.8 \%$ with $92.8 \%$ of the respondents being female. Out of the reported episodes of violence, $53.2 \%$ were committed by patients towards nurses. This consistency in prevalence demonstrates the threat nurses face on a daily basis. The report also noted that $73 \%$ of nurses experienced some form of violence occasionally, $17 \%$ reported violence often, and $1.7 \%$ described workplace violence as always been experienced. In Paul, Zhiqing and Xin Xuan (2013)'s review of 136 articles, about one third of nurses' worldwide indicated exposure to physical violence and bullying, one third reported injury, about a quarter experienced sexual harassment, and about two-third indicated nonphysical violence. This evidence clearly identifies that exposure to violence in health care is common with half of all workers reporting exposure (Abodunrin, Adeoye, Adeomi and Akande, 2014; Ogbonnaya, Ukegbu, Aguwa and Emma-Ukaegbu, 2012; Clark, 2016).

On the other hand, research has also submitted that workplace violence against nurses is under reported, scattered and sketchy. A large study of more than 4,738 Minnesota nurses as reported by Clark (2016) and 
OSHA (2015) revealed that only $69 \%$ of physical episodes of violence were reported, $71 \%$ of nonphysical acts of violence were never reported. Even when these incidents were reported, $86 \%$ were reported verbally without adequate follow- up. The evidence for non-reporting contributes a remarkable view of a possible additional problem related to violence in health care and the impact on nurses.

\subsubsection{Effects of Workplace Violence on Nurses and Nurses' Work Productivity}

Violence undermines the healing mission of the healthcare organization, jeopardizes the physical and emotional safety of patients and caregivers and interferes with the ability of the healthcare team to optimally contribute to positive patient outcomes (American Association of Critical Care Nurses, (AACN), 2014)

The resultant effects of workplace violence are multi-factorial impacting the individual nurse, the organization, and the profession. Azodo, Ezeja and Ehikhamenor (2011) posits that violence can result in pain, distress, disability or death, negatively affecting productivity due to reduced morale and motivation.

Physical attacks are obviously dangerous but serious or persistent verbal abuse and threats can also damage employees' health through anxiety or stress (Wurim, 2013). The impact of physical injury is self-explanatory resulting in mostly minor injuries, thus having an obvious impact on health (Wurim, 2013).

Effects of physical violence on the nurse include acute stress, posttraumatic stress symptoms, decreased work productivity, physical injury, and death (Bureau of Labour Statistics, (2012); Gates, Gillespie, \& Succop, (2011); Gillespie, Gates, Miller, \& Howard, (2010); and Janocha and Smith, (2010). Though work-related deaths are a rare occurrence in health care, Janocha and Smith (2010) reported 100 fatally injured workers between 2003 and 2007 in the health care and social assistance sector due to workplace violence, and of all the non-fatal injuries that occurred in the private sector in 2007, approximately 9,953 (59.1\%) occurred in the health care and social assistance sector (Janocha and Smith, 2010). Specific to emergency nursing, the degree of physical assaults against emergency nurses was 1.8 assaults per nurse per year (Kowalenko, Gates, Gillespie, Succop, and Mentzel, 2013). A mutual response shared by nurses as victims of physical violence in the workplace includes becoming fearful, angry, frustrated, and helpless (Gillespie, Gates, Miller, and Howard, 2010; Magnavita and Heponiemi, 2011; Samir, Mohamed, Moustafa, and AbouSaif, 2012). Most frequently too, nurses display signs of posttraumatic stress after physical violence. Such signs include consciously avoiding opportunities to talk about the event, having recurrent flashbacks about the event, and having a heightened state of arousal leading to poor sleeping (AbuAlRub and Al-Asmar, 2011; Gates, Gillespie, \& Succop, 2011; Gillespie, Gates, Miller, \& Howard, 2010; Pai and Lee, 2011). Emergency department nurses reported that they were unable to work in the emergency department after a violent incident (Howerton, Child, and Mentes, 2010).

Consequences of physical violence are not limited to adverse psychological signs and symptoms. Being the target of physical violence can impact the ability of nurses to perform optimally. Gates, Gillespie, and Succop (2011) submitted that the posttraumatic stress symptoms caused by physical violence reduces the ability of emergency nurses to cognitively focus on their work when compared to their ability prior to a violent event. When Gillespie, Gates, Miller, \& Howard, 2010 qualitatively explored the effect of workplace violence on nurses in a paediatric emergency department, it was found that participants intentionally avoided patients and visitors who were violent, likely in an effort to prevent a recurrent violent act. This then posits that while physical violence can lead to negative psychological health, it can also lead to a decrease in work productivity evidenced in the quality of care being rendered to patients.

The occurrence of WPV continues to be an issue that impacts individuals, organizations, and the profession of nursing. There is clear and compelling evidence that workplace violence in health care has numerous effects. Twenty years of research has indicated that this is not only a health care problem but a social concern. In light of the many challenges that health care is currently experiencing, workplace violence should be considered a priority. As a public concern, a preventive framework was instituted, but the effectiveness of these strategies has continued to be another challenge in mitigating workplace violence.

\section{Methods}

\subsection{Design}

A descriptive study design was used to determine the pattern of workplace violence and perceived effects on nurses' work productivity. Two trained research assistants collected data in each of the health facilities.

\subsection{Sample and Settings}

A convenience sample was used. Nurses working in 2 selected health facilities ( 1 federal and 1 state hospital) were recruited. These hospitals have the highest population of nurses and client flow as compared to other 
hospitals in Ibadan city. Sampling criteria include all nurses especially nurses with recent exposure to violence. Nurses who have spent less than 3 months in the selected hospital were excluded.

\subsection{Data Collection}

Two trained research assistants collected data. All nurses working in the targeted hospital were approached to participate in the study. The trained research assistants visited the different hospital departments to explain the purpose of the study and to invite nurses to voluntarily participate. Upon agreeing to participate, they were asked to read and sign the consent form and then complete the questionnaire. Due to the busy schedule and job task of nurses, the three shifts were employed in data collection. Some nurses were assessed during their break period, some filled the questionnaire on the spot and returned it immediately while some were collected by the nurses and retrieved later. Data collection took a span of one month before completion. A total of 314 nurses completed the questionnaire with a response rate of $90 \%$. All completed questionnaires were valid for use.

\subsection{Data Analysis}

Statistical Package of Social Science (SPSS) version 21 (SPSS Inc., Chicago, IL, USA) was used to conduct descriptive and correlation statistics.

\subsection{Ethical Considerations}

Before conducting the study, the researcher obtained approval from the Institutional Review Board at the University of Ibadan and Ministry of Health, Oyo State. Confidentiality was maintained throughout the study. Participants' anonymity was ensured by not asking the participants to write any identifying information on the questionnaire. There was no potential risk to participation and nurses were informed that they could quit at any time in case they preferred not to complete the questionnaire.

\subsection{Measures}

Two instruments were combined for use in the present study. The first is an adapted interviewer administered questionnaire, derived from the International Labour Organization (ILO), International Council of Nurses (ICN), WHO, and Public Services International (PSI) joint program project "Workplace Violence in the Health Sector Country Case Studies Research Instruments Survey Questionnaire". This Workplace Violence Questionnaire (WVQ) was previously used to examine workplace violence by researchers in Jordan (AbuAlRub and Al-Asmar 2011; Ahmed 2012; Al-Omari, 2015) and in other countries, such as Taiwan (Chen, Hwu and Wang, 2009) and Hong Kong (Kwok, Law, Li, Ng, Cheung, Fung et.al, 2006). A letter requesting for permission to use the instrument was sent to WHO. Worthy of note is the fact that not all the items in the instrument was adapted. Relevant questions from the 5 sections in the instrument were picked and modified to suite the first two sections (section A- socio demographic data and section B- pattern of workplace violence) of the questionnaire for use in this study.

On the other hand, an investigator developed health care productivity survey was entirely adopted for use in the present study. This survey was developed and tested by Gillespie, Gates and Succop in 2010 in a bid to measure the change in work productivity following a stressful event of workplace violence. Psychometric analysis of this instrument demonstrated strong content and construct validity for the four subscales, internal consistency reliability $(0.871-0.945)$, and test re-test reliability $(r=0.801, p<0.001)$ with a sample of U.S. emergency nurses (Gillespie, Gates and Succop, 2010). Request for permission to use the instrument was sent to Dr Gillespie and was adequately granted.

The questionnaire contained 64 items in all (63 closed and 1 open-ended question), categorized into four sections: demographic data ( 8 items), pattern of workplace violence (22 items), determinants of workplace violence (5 items) and perceived effects of workplace violence on nurses' work productivity (29 items).

Section A and B was derived and modified from the WVQ, section C was developed from literature review and section $\mathrm{D}$ was adopted from the health care productivity survey. 


\section{Results}

Table 1. Socio-demographic characteristics of participants $(N=314)$

\begin{tabular}{|c|c|c|c|}
\hline Variables & $\begin{array}{l}\text { Frequency } \\
\text { f }\end{array}$ & Percentage $\%$ & Mean Std. D \\
\hline \multicolumn{4}{|l|}{ Age group } \\
\hline $24-38$ years & 164 & 52.2 & \\
\hline $39-57$ years & 150 & 47.8 & $38.6 \pm 6.5$ \\
\hline \multicolumn{4}{|l|}{ Gender } \\
\hline Male & 7 & 2.2 & \\
\hline Female & 307 & 97.8 & \\
\hline \multicolumn{4}{|l|}{ Marital status } \\
\hline Single & 28 & 8.9 & \\
\hline Cohabiting (Living as married) & 1 & 0.3 & \\
\hline Married & 280 & 89.2 & \\
\hline Widowed & 3 & 1 & \\
\hline Separated/Divorced & 2 & 0.6 & \\
\hline \multicolumn{4}{|l|}{ Highest level of education } \\
\hline Diploma e.g., RN, RN/RM & 147 & 46.8 & \\
\hline Bachelor's degree in nursing e.g., BSc, BNSc & 115 & 36.6 & \\
\hline Bachelor's degree in other fields & 35 & 11.1 & \\
\hline Master's degree in Nursing & 1 & 0.3 & \\
\hline $\begin{array}{l}\text { Master's degree in other fields e.g., Edu, Nut, Medical } \\
\text { sociology }\end{array}$ & 16 & 5.1 & \\
\hline \multicolumn{4}{|l|}{ Professional status } \\
\hline Nursing Officer (NO) II & 77 & 24.5 & \\
\hline Nursing Officer (NO) I & 49 & 15.6 & \\
\hline Senior Nursing Officer (SNO) & 46 & 14.6 & \\
\hline Principal Nursing Officer (PNO) & 12 & 3.8 & \\
\hline Assistant Chief Nursing Officer (ACNO) & 66 & 21 & \\
\hline Chief Nursing Officer (CNO) & 56 & 17.8 & \\
\hline Assistant Director of Nursing (ADN) & 8 & 2.5 & \\
\hline \multicolumn{4}{|l|}{ Post qualification years of experience } \\
\hline$(2-10)$ years & 125 & 39.8 & \\
\hline$(11-20)$ years & 151 & 48.1 & $13.2 \pm 6.08$ \\
\hline$(21-32)$ years & 38 & 12.1 & \\
\hline \multicolumn{4}{|l|}{ Unit of practice } \\
\hline Emergency & 38 & 12.1 & \\
\hline Intensive care & 23 & 7.3 & \\
\hline Paediatrics & 81 & 25.8 & \\
\hline General Outpatients & 44 & 14 & \\
\hline Medicine/ Surgery & 103 & 32.8 & \\
\hline Maternal and Child Health & 1 & 0.3 & \\
\hline Obstetrics and Gynaecology & 24 & 7.6 & \\
\hline
\end{tabular}


Of the 349 nurses who participated in the study, a total of 314 completed the questionnaire. Most of the participants are female $(97.8 \%)$, aged 38 years or younger $(52.2 \%)$, married $(89.2 \%)$, had a diploma in nursing (46.8\%) and work experience of $11-20$ years $(48.1 \%)$.

Table 2. Respondents' pattern and experience of WPV $(\mathrm{N}=314)$

\begin{tabular}{|c|c|c|c|}
\hline Variables & Response & $\begin{array}{l}\text { Physical violence } \\
\text { f (\%) }\end{array}$ & $\begin{array}{l}\text { Psychological violence } \\
\text { f (\%) }\end{array}$ \\
\hline \multirow{2}{*}{$\begin{array}{l}\text { Experience of } \\
\text { WPV }\end{array}$} & Yes & $50(15.9)$ & $87(27.7)$ \\
\hline & No & $264(84.1)$ & $227(72.3)$ \\
\hline \multirow[t]{3}{*}{$\begin{array}{l}\text { Description of } \\
\text { violence }\end{array}$} & $\begin{array}{l}\text { Physical violence with } \\
\text { a weapon }\end{array}$ & $1(0.3)$ & …......... \\
\hline & $\begin{array}{l}\text { Physical violence } \\
\text { without a weapon }\end{array}$ & & \\
\hline & & $49(15.6)$ & $\ldots \ldots \ldots \ldots \ldots$ \\
\hline \multirow{2}{*}{$\begin{array}{l}\text { Violence as a } \\
\text { common } \\
\text { incidence in the } \\
\text { workplace }\end{array}$} & Yes & $39(12.4)$ & $60(19.1)$ \\
\hline & No & $34(10.8)$ & $28(8.9)$ \\
\hline \multirow[t]{7}{*}{ Attacker } & Patient & $11(3.5)$ & $8(2.5)$ \\
\hline & Patient relative & & \\
\hline & Staff member & $33(10.5)$ & $37(11.8)$ \\
\hline & $\begin{array}{l}\text { Management/ } \\
\text { supervisor }\end{array}$ & & \\
\hline & External colleague & $6(1.9)$ & $19(6.1)$ \\
\hline & & ........... & $10(3.2)$ \\
\hline & & $\ldots$ & $3(1.0)$ \\
\hline
\end{tabular}

\subsection{Pattern of Workplace Violence}

Shockingly, $15.9 \%$ of the sample they were physically attacked in the workplace during the past 12 months, of which only 1 reported being physically attacked with a weapon. On the other hand, $27.7 \%$ experienced psychological WPV in the last 12 months, with the most common form being verbal abuse 67 (21.3) and harassment $10(3.2 \%)$. Out of 71 participants who responded to the question of whether physical violence is a common occurrence in the workplace, 39 (12.4) said Yes and 34 (10.8) said No. Likewise, for psychological violence, out of the 88 participants who responded, 60 (19.1) confirmed that psychological violence is a typical incident in the workplace. The major attacker for both the physical and psychological violence were the patient relatives, 33 (10.5) and 37 (11.8) respectively. 
Table 3. Measure of nurses' work productivity

\begin{tabular}{|c|c|c|c|}
\hline $\begin{array}{l}\text { Measure } \\
\text { productivity }\end{array}$ & $\begin{array}{l}\text { Decreased productivity } \\
\text { f }(\%)\end{array}$ & $\begin{array}{l}\text { No change in } \\
\text { productivity } \\
\text { f (\%) }\end{array}$ & $\begin{array}{l}\text { Increased } \\
\text { productivity } \\
\text { f }(\%)\end{array}$ \\
\hline Concentration on work & $46(14.6)$ & $216(68.8)$ & $52(16.6)$ \\
\hline Attention to details & $32(10.2)$ & $220(70.1)$ & $62(19.8)$ \\
\hline $\begin{array}{l}\text { Timely completion of } \\
\text { documentation }\end{array}$ & $36(11.5)$ & $220(70.1)$ & $58(18.5)$ \\
\hline $\begin{array}{l}\text { Safe medication } \\
\text { administration }\end{array}$ & $8(2.5)$ & $228(72.6)$ & $78(24.8)$ \\
\hline $\begin{array}{ll}\text { Provision } & \text { of } \\
\text { compassionate care }\end{array}$ & $40(12.8)$ & $209(66.6)$ & $65(20.7)$ \\
\hline $\begin{array}{l}\text { Timely completion of } \\
\text { patient care }\end{array}$ & $38(12.1)$ & $220(70)$ & $46(17.8)$ \\
\hline $\begin{array}{l}\text { Collaboration of } \\
\text { patient care with other } \\
\text { employees }\end{array}$ & $25(7.9)$ & $225(71.6)$ & $64(20.4)$ \\
\hline $\begin{array}{l}\text { Advocacy for patients' } \\
\text { needs }\end{array}$ & $54(17.2)$ & $202(64.3)$ & $58(18.5)$ \\
\hline $\begin{array}{l}\text { Provision of emotional } \\
\text { to all family members }\end{array}$ & $53(16.9)$ & $210(66.9)$ & $51(16.2)$ \\
\hline $\begin{array}{l}\text { Empathy with patients } \\
\text { and family members }\end{array}$ & $50(15.9)$ & $207(65.9)$ & $57(18.1)$ \\
\hline
\end{tabular}

Table 4. Levels of nurses' work productivity

\begin{tabular}{llllllll}
\hline Levels of work productivity & Frequency & Percent & Scores & Min & Max & Mean & Std. D \\
\hline Decreased work productivity & 60 & 19.1 & -40 to -1 & & & & \\
\hline No change in work productivity & 170 & 54.1 & 0 & -40 & 58 & 5.61 & 19.32 \\
\hline Increased work productivity & 84 & 26.8 & 1 to 58 & & & & \\
\hline Total & $\mathbf{3 1 4}$ & $\mathbf{1 0 0 . 0}$ & & & & & \\
\hline
\end{tabular}

\subsection{Perceived Effects of Workplace Violence}

While $19.1 \%$ of the respondents perceived that workplace violence can result in decreased work productivity, $54.1 \%$ perceived that there is no change in work productivity and $26.8 \%$ were of the opinion that workplace violence can result in increased work productivity.

\section{Discussion}

The current study described the pattern of workplace violence and perceived effects on work productivity among nurses working in selected hospitals in Ibadan. The findings indicate that both physical and psychological violence are prevalent in the study setting with psychological violence having the highest prevalence. This implies that nurses working within the health care delivery system experience both forms of violence simultaneously depending on what form of violence the attacker employs. This is in tandem with the findings of Abodunrin, Adeoye, Adeomi and Akande, 2014; and Al-Omari, 2015. Abodunrin, Adeoye, Adeomi and Akande's study on prevalence and forms of violence against health care professionals in a South-Western city, Nigeria reported a high prevalence of violence (physical abuse) against nurses. The study of Al-Omari (2015) on physical and verbal workplace violence against nurses in Jordan also reported a high prevalence of violence.

A remarkable finding from the present study revealed that both physical and psychological violence are typical 
incidents that occur in the health facilities, with physical violence without a weapon and verbal abuse having the highest prevalence followed by harassment and threat. This prevalence is similar to the previous studies of Abodunrin, Adeoye, Adeomi and Akande, 2014; Magnavita and Heponiemi, 2012; and Luoto-Korhola and Niskanen, 2012; suggesting the fact that violence against health care professionals especially nurses is resident in health facilities and for whatever reason it is perpetrated, the practice is unruly, unacceptable and uncalled for as it has dire consequences not only on the health worker affected but also on the attacker, the health facility and the health care delivery system as a whole. Hence, there is the need to tackle the menace of violence in the workplace through the formulation and implementation of policies, legislations and procedures such as zero tolerance of workplace violence.

It is apparent that the major instigators of WPV are more often patient relatives followed by patient themselves, the principal people with whom nurses interact regularly (Boafo \& Hancock, 2017; 'Teymourzadeh, Rashidian, Arab, Akbari-Sari and Hakimzadeh, 2014). However, most studies (Al- Omari, 2015; Mingli, et al, 2015; Abodunrin, Adeoye, Adeomi and Akande, 2014; Kwok et al, 2006) on the contrary, indicated patients as the sole source of violence followed by their relatives. The explanation for this can be deduced from the fact that patient relatives are allowed access to their sick family member, hence their involvement in patient care which could result in violence when events do not turn out as expected. However, with this situation, an important strategy in reducing such violence should be constant interactions and effective communication with the patient relatives.

Furthermore, the researcher is not oblivious of the finding that patient relatives and patients are not the sole perpetrators of workplace violence, nursing colleagues, members of staff, managers and supervisors were also indicated as sources which is also consistent with Mingli, et al, 2015; Luoto-Korhola and Niskanen, 2012; Kwok, et al, 2006. Violence undertaken by other members of the health care team is known as internal violence and can either be lateral or vertical. Lateral violence occurs between workers of the same status, e.g. nurse-to nurse. Vertical violence on the other hand involves senior colleagues and subordinates (Mingli, et al, 2015). In this study, it was discovered that $6.1 \%$ of internal violence was lateral while $3.2 \%$ was vertical violence. This finding is not expected to be overlooked as it serves as an insight into the sort of inter/ intrapersonal and inter/ intra professional relationships that exist between members of the health care team. It is quite disturbing and hence, requires much more attention than earlier thought.

Moreover, inappropriate reporting and/ or under reporting of violence as reported in the present study may also be explained in line with the findings of Abodunrin, Adeoye, Adeomi \& Akande, (2014) and Howerton, Child \& Mentes (2010), that nurses may have viewed the violent occurrences as minor, not seen as an assault or have been resolved amicably; coupled with differing definition and interpretation of violence thereby contributing to an increased threshold for insult and pain. As a way of improving on this, nurses and every other member of the health care system need to be aware of their rights and responsibilities, part of which is the right to a safe working environment. Effective training on workplace violence will also be of great importance.

On the perceived effects of workplace violence on nurses' work productivity, a fair proportion of the respondents consented to the fact that exposure to violence can result in a decrease in the work productivity of nurses. Even though the proportion is fair, it can be counted as significant to this study. This is because violence in the workplace, either large or small in magnitude is not to be overlooked due to the unpalatable effects it produces in the affected persons. This is similar to the findings of the Bureau of Labour Statistics, (2012); Gates, Gillespie, and Succop, (2011); and Gillespie, Gates, Miller, and Howard, (2010) who concluded that acute stress, posttraumatic stress symptoms, decreased work productivity, physical injury, and death are the main effects of WPV on nurses.

On another hand, the fact that a larger proportion of the respondents opined that there is no change in productivity can be explained in line with the nurses' individual definition, interpretation and perception of violence as well as the ethical obligations guiding the profession, and as such are expected to ensure the standards are maintained irrespective of the negativities they encounter. Hence nursing duties rendered to patients may not be affected. Nevertheless, the researcher is of the opinion that the work environment be made more convenient, conducive, stress-free and friendly as this will bring out the best in the workers.

\section{Conclusion}

The findings of this study revealed the prevalent occurrence of violence against nurses. A significant portion of the nurses were exposed to physical and verbal violence and the main instigators were patient relatives. Internal violence was also found to be resident among nurses. Though, all of these forms of violence were viewed as inconsequential by the nurses, it has proven to have a lot of impact on their productivity as key members of the health care delivery team. 


\section{Acknowledgement}

I appreciate Dr Gillespie and his colleagues for allowing me use the health care productivity survey instrument in my study.

\section{References}

Abbas, M., Fiala, L., Amira, G., AbdelRahman, A., \& Fahim, A. (2010). Epidemiology of workplace violence against staff in Ismaila governorate, Egypt. Journal of the Egyptian Public Health Association, 85(1-2), 29-43. Retrieved August 28, 2016, from http://www.epha.eg.net/pdf/n1-2-2010/2/pdf

Abodunrin, O., Adeoye, O., Adeomi, A., \& Akande, T. (2014). Prevalence and forms of violence against health care professionals in a South-Western city, Nigeria. Sky Journal of Medicine and Medical Sciences, 2(8), 67-72. Retrieved January 12, 2016, from http://www.skyjournals.org/sjmms/pdf/2014pdf/Oct/Abodunrin\%20et\%20al\%20pdf

AbuAlrub, R., \& Al-Asmar, A. (2011). Physical violence in workplace among Jordanian hospital nurses. Journal of Transcultural Nursing, 22, 157-165.

Ahmed, A. (2012). Verbal and physical abuse against Jordanian nurses in the work environment. Eastern Mediterranean Health Journal, 18, 318-324.

Akpabio, I., John, M., Akpan, M., Akpabio, F., \& Uyanah, D. (2016). Work-related conflict and nurses' role performance in a tertiary hospital in South-South Nigeria. Journal of Nursing Education and Practice, 6(2), https://doi.org/10.5430/jnep.V6n20p106

Al-Omari, H. (2015). Physical and verbal workplace violence against nurses in Jordan. International Nursing Review, 62(1), 111-118. Retrieved February 8, 2016, from http://www.ncbi.nlm.nih.gov/pubmed/25626758

Algwaiz, N., \& Alghanim, S. (2012). Violence exposure among health care professionals in Saudi public hospitals: a preliminary investigation. Saudi Medical Journal, 33, 76-82.

Alyaemni, A., \& Hana, A. (2016). Workplace violence against nurses in the emergency departments of three hospitals in Riyadh, Saudi Arabia: A cross sectional survey. Nursingplusopen. Retrieved January 7, 2017, from http://www.nursingplusopen.com/article/S2352-9008 (16)30014-0/fulltext

Asmaa, A., \& Hana, A. (2016). Workplace violence against nurses in the emergency departments of three hospitals in Ridyah, Saudi Arabia: a cross-sectional survey. Nursingplusopen, http://doi.org/10.1016/j.npls.2016.09.001

Azodo, C., Ezeja, E., \& Ehikhamenor, E. (2011). Occupational violence against dental professionals in Southern Nigeria. African Health Sciences, 11, 486-492.

Boafo, I., \& Hancock, P. (2017). Workplace violence against nurses: a cross-sectional descriptive study of Ghanaian nurses. Sage Journals, 7(1). https://doi.org/10.1177/2158244017701187

Chen, W., Hwu, H., \& Wang, J. (2009). Hospital staff responses to workplace violence in a psychiatric hospital in Taiwan. International Journal of Occupational Environmental Health, 15, 173-179. https://doi.org/10.1179/oeh.2009.15.2.173

Clark, K. (2016). The aftermath of violence: The lived experience phenomena of assault in nursing. Walden university scholar works.

Conrad, K., Balch, G., Reichelt, P., Muran, S., \& Oh, K. (1994). Musculoskeletal injuries from fire services: views from a focus study. $A A O H N, 42,572-581$.

Cooper, L., \& Swanson, N. Workplace violence in the health sector: state of the art. Retrieved February 8, 2016, from http://www.who.int/violence_injury_prevention/injury/en/WVstateart.pdf

Fasanya, B., \& Dada, E. (2015). Caregivers' concerns- age group issues on workplace violence. Sciencedirect, 3, 227-233. Retrieved February 18, 2016, from http://www.sciencedirect.com/science/article/pii/S2351978915001341

Ferns, T. (2012). Recording violent incidences in the emergency department. Nursing Standard, 26(28), 40-48.

Fute, M., Mengesha, Z., Wakgari, N., \& Tessema, G. (2015). High prevalence of workplace violence among nurses working at public health facilities in Southern Ethiopia. BMC Nursing, 14, 9.

Gacki-Smith, J., Juarez, A. M., Boyett, L., Homeyer, C., Robinson, L., \& Maclean, S. (2010). Violence against nurses working in US emergency departments. Journal of Nursing Administration, 39(7-8), 340-349. 
Retrieved

from https://urgentmatters.org/media/file/Violence\%20Against\%20Nurses\%20Working\%20in\%20US\%20Emerg ency\%20Departments.pdf

Gates, D., Gillespie, G., \& Succop, P. (2011). Violence against nurses and its impact on stress and productivity. Nursing Economics, 29(2), 59-67. Retrieved August 16, 2016, from https://www.medscape.com/viewarticle/746092-4

Gillespie, G. (2008). Violence against health care workers in a pediatric emergency department. College of Nursing and Health. Retrieved March 30, 2016, from https://etd.ohiolink.edu/!etd.send_file?accession=ucin1212109392\&disposition=inline

Gillespie, G. (2013). Stressful Incidents of Physical Violence against Emergency Nurses. The Online Journal of Issues in Nursing, 18(1), Retrieved March 31, 2016, from http://www.medscape.com/viewarticle/807942_4

Gillespie, G. L., Gates, D. M., \& Succop, P. (2010). Psychometrics of the Healthcare Productivity Survey. Advanced Emergency Nursing Journal, 32(3), 258-271. https://doi.org/10.1097/TME.0b013e3181e97510

Gillespie, G., Gates, D., Miller, M., \& Howard, P. (2010). Violence against health care workers in a paediatric emergency department. Advanced Emergency Nursing Journal, 32(1), 68-82.

Hahn, S., Hantikainen, V., Needham, I., Kok, G., Dassen, T., \& Halfens, R. (2012). Patient and visitor violence in general hospital, occurrence, staff interventions and consequences: a cross sectional survey. Journal of Advanced Nursing, 68(12), 2685-2699.

Howerton, Child, R., \& Mentes, J. (2010). Violence against women: the phenomenon of workplace violence against nurses. Issues in Mental Health Nursing, 3(12), 89-95.

International Labour Office, International Council of Nurses, World Health Organization, \& Public Services International. (2003). Workplace violence in the health sector: country case studies research instruments survey questionnaire (English). ILO/ICN/WHO/PSI joint program on workplace violence in the health sector, Geneva.

Khoshknab, M., Tamizi, Z., Ghazanfari, N., \& Mehrabani. G. (2012). Prevalence of workplace violence in psychiatric wards, Tehran, Iran. Pakistan Journal of Biological Sciences, 15(14), 680-684. Retrieved January 20, 2016, from https://www.ncbi.nlm.nih.gov/pubmed/24171249

Kowalenko, T., Gates, D., Gillespie, G., Succop, P., \& Mentzel, T. (2013). Prospective study of violence against emergency department workers. The American Journal of Emergency Medicine, 31(1), 197-205. Retrieved February 28, 2016, from https://www.ajemjournal.com/article/S0735-6757(12)00369-5/fulltext

Kvas, A., \& Selijak, J. (2014). Unreported workplace violence in nursing. International Nursing Review, 61(3), 344-351. Retrieved January 22, 2016, from https://onlinelibrary.wiley.com/doi/10.1111/inr.12106/abstract\#publication-history

Kwok, R., Law, Y., Li, K., Ng, Y., Cheung, M., ... Leung, W. (2006). Prevalence of workplace violence against nurses in Hong Kong. Hong Kong Medical Journal, 12(1), 6-9. Retrieved January 21, 2017, from https://www.ncbi.nlm.nih.gov/pubmed/16495582

Luoto-Korhola, T., \& Niskanen, S. (2012). Workplace violence against nursing personnel: a literature review. JAMK University of Applied Sciences. Retrieved from https://publications.theseus.fi/bitstream/handle/10024/48872/Luoto-korhola-tuuli-Niskanen-susanna.pdf...P df? Sequence $=1$

Magnavita, N., \& Heponiemi, T. (2012). Violence towards health care workers in a public health facility in Italy: a repeated cross sectional study. BMC Health Services Research, 12, 108.

McPhaul, K., Lipscomb, J., \& Johnson, J. (2010). Assessing risk for violence on home health visits. Home Healthcare Nurse, 28(5), 278-289. Retrieved February 12, 2016, from http://www.ncbi.nlm.nih.gov/pubmed/20463511

Mingli, J., Ning, N., Ye, L., Lijun, G., Yu, C., ... Yanhua, H. (2015). BMJ Open, 5(3), e006719. Retrieved from https://www.ncbi.nlm.nih.gov/pmc/articles/PMC4386227/

Mohamed, K., \& Motasem, H. (2012). Workplace violence against physicians and nurses in Palestinian public hospitals: a cross sectional study. BMC Health Services Research, 12, 469.

Nakaishi, L., Moss, H., Weinstein, M., Perrin, N., Rose, L., ... Glass, N. (2013). Exploring workplace violence 
among home care workers in a consumer-driven home health care program. Workplace health and safety, 61(10), 441-450. Retrieved January 12, 2016, from http://www.ncbi.nlm.nih.gov/pubmed/24053217

National Institute for Occupational Safety and Health (NIOSH). (2015). Workplace violence prevention for nurses. Retrieved January 20, 2016, from http://www.cdc.gov/niosh/topics/violence/

Occupational Safety and Health Administration (OSHA). (2015). Guidelines for preventing workplace violence for healthcare and social service workers. Retrieved January 20, 2016, from https://www.oshagov/Publications/OSHA3826.pdf

Ogbonnaya, G., Ukegbu, A., Aguwa, E., \& Emma-Ukaegbu, U. (2012). A study on workplace violence against health workers in a Nigerian tertiary hospital. Nigerian Journal of Medicine, 21(2), 174-179. Retrieved February 8, 2016, from http://www.ncbi.nlm.nih.gov/pubmed/23311186

Papa, A., \& Venella, J. (2013). Workplace violence in health care: Strategies for advocacy. Online Journal of Issues in Nursing, 18(1), 5. Retrieved February 28, 2016, from https://www.ncbi.nlm.nih.gov/pubmed/23452201

Paul, E., Zhiqing, E., \& Xin Xuan, C. (2013). Nurse exposure to physical and nonphysical violence, bullying, and sexual harassment: A quantitative review. International Journal of Nursing Studies, 51(1), 72-84. Retrieved January 22, 2016, from http://www.journalofnursingstudies.com/article/S0020-7489(13)00035-7/abstract

Peihang, S., Xue, Z., Yihua, S., Hongkun, M., Mingli, J., Kai, X., .. Mei, Y. (2017). Workplace violence against health care workers in North Chinese hospitals: A cross sectional survey. International Journal of Environmental Research and Public Health. Retrieved February 18, 2017, from www.mdpi.com/1660-4601/14/1/96/htm

Samir, N., Mohammed, R., Moustafa, E., \& Abou Saif, H. (2012). Nurses' attitudes and reactions to workplace violence in obstetrics and gynaecology depatments in Cairo hospitals. East Mediterranean Health Journal, 18(3), 198-204.

Spector, P., Zhou, Z., \& Che, X. (2014). Nurses' exposure to physical and nonphysical violence, bullying and sexual harassment: A quantitative review. International Journal of Nursing Studies, 51(1), 72-84.

Swan, J., \& Mitus, M. (2014). Workplace violence. Online nursing continuing education. Retrieved April 13, 2016, from http://www.nursingceu.com/courses/455/index_nceu.html

Taylor, J., \& Rew, L. (2011). A systematic review of literature: workplace violence in the emergency department. Journal of Clinical Nursing, 20(7-8), 1072-1085. Retrieved from https://www.ncbi.nlm.nih.gov/pubmed/20846214

Teymourzadeh, E., Rashidian, T., Arab, M., Akbari-Sari, A., \& Hakimzadeh, S. (2014). Nurses exposure to workplace violence in a large teaching hospital in Iran. International Journal of Health Policy and Management, 3(6), 301-305. Retrieved from https://www.ijhpm.com/MKmNZ/article_2896_607.html

U.S. Department of Labour Occupational Safety and Health Administration. (2015). Retrieved January 12, 2016, from https://www.osha.gov/publications/osha3148.pdf

Workplace violence in the health sector Country case studies research instruments: Guidelines for focus group discussion. International Labour Office (ILO), International Council of Nurses (ICN), World Health Organization (WHO) \& Public Services International (PSI) Joint Programme on Workplace Violence in the Health Sector. (2003). Retrieved February 8, 2016, from http://www.who.int/violence_injury_prevention/violence/interpersonal/en/WVfocusgroupdiscussion.pdf?ua $=1$

Workplace violence in the health sector Country case studies research instruments: Research protocol-Sample design. International Labour Office (ILO), International Council of Nurses (ICN), World Health Organization (WHO) and Public Services International (PSI) Joint Programme on Workplace Violence in the Health Sector. 2003. Retrieved February 8, 2016, from http://www.who.int/violence_injury_prevention/violence/interpersonal/en/WV_sampledesign.pdf?ua=1

Workplace violence in the health sector Country case studies research instruments: Research protocol. International Labour Office (ILO), International Council of Nurses (ICN), World Health Organization (WHO) and Public Services International (PSI) Joint Programme on Workplace Violence in the Health Sector. (2003). Retrieved February $\quad 8, \quad 2016, \quad$ from 
http://www.who.int/violence_injury_prevention/violence/interpersonal/en/WVresearchprotocol.pdf?ua=1

Workplace violence in the health sector Country case studies research instruments: Survey questionnaire. International Labour Office (ILO), International Council of Nurses (ICN), World Health Organization (WHO) and Public Services International (PSI) Joint Programme on Workplace Violence in the Health $\begin{array}{llllll}\text { Sector. } & \text { (2003). } & \text { Retrieved } & \text { April } & \text { 2014, }\end{array}$ http://www.who.int/violence_injury_prevention/violence/interpersonal/en/WVquestionnaire.pdf

World Health Organization. Global campaign for violence prevention: Violence prevention alliance. (2012). Retrieved January 20, 2016, from http:/www.who.int/violenceprevention/approach/definition/en/

Wurim, B. (2013). Workplace Violence and the Cost-Benefit Trade Off of Zero-Tolerance Safety Policies in Central Nigerian Hospitals. International Journal of Business and Social Science, 4(8). Retrieved February 8, 2016, from http://ijbssnet.com/journals/Vol_4_No_8_Special_Issue_July_2013/21

\section{Copyrights}

Copyright for this article is retained by the author(s), with first publication rights granted to the journal.

This is an open-access article distributed under the terms and conditions of the Creative Commons Attribution license (http://creativecommons.org/licenses/by/4.0/). 